\title{
Role of radiatively forced temperature changes in enhanced semi-arid warming in the cold season over east Asia
}

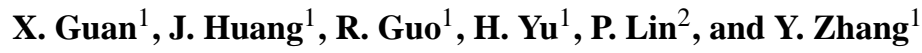 \\ ${ }^{1}$ Key Laboratory for Semi-Arid Climate Change of the Ministry of Education, College of Atmospheric Sciences, \\ Lanzhou University, 730000 Lanzhou, China \\ ${ }^{2}$ Program in Atmospheric and Oceanic Sciences, Princeton University, 08544 Princeton, New Jersey, USA
}

Correspondence to: J. Huang (hjp@lzu.edu.cn)

Received: 28 June 2015 - Published in Atmos. Chem. Phys. Discuss.: 27 August 2015

Revised: 28 November 2015 - Accepted: 4 December 2015 - Published: 15 December 2015

\begin{abstract}
As climate change has occurred over east Asia since the 1950s, intense interest and debate have arisen concerning the contribution of human activities to the observed warming in past decades. In this study, we investigate regional surface temperature change during the boreal cold season using a recently developed methodology that can successfully identify and separate the dynamically induced temperature (DIT) and radiatively forced temperature (RFT) changes in raw surface air temperature (SAT) data. For regional averages, DIT and RFT contribute 44 and $56 \%$ to the SAT over east Asia, respectively. The DIT changes dominate the SAT decadal variability and are mainly determined by internal climate variability, represented by the North Atlantic Oscillation (NAO), Pacific Decadal Oscillation (PDO), and Atlantic Multi-decadal Oscillation (AMO). Radiatively forced SAT changes have made a major contribution to the global-scale warming trend and the regionalscale enhanced semi-arid warming (ESAW). Such enhanced warming is also found in radiatively forced daily maximum and minimum SAT. The long-term global-mean SAT warming trend is mainly related to radiative forcing produced by global well-mixed greenhouse gases. The regional anthropogenic radiative forcing, however, caused the enhanced warming in the semi-arid region, which may be closely associated with local human activities. Finally, the relationship between the so-called "global warming hiatus" and regional enhanced warming is discussed.
\end{abstract}

\section{Introduction}

Asia is arguably the most sensitive area to climate change, because it comprises almost $39 \%$ of the world's land area (White and Nackoney, 2003; Huang et al., 2013) and supports 4 billion people, which accounts for $66.67 \%$ of the world population. A great portion of its drylands have shown a most significantly enhanced warming in the boreal cold season over mid- to high-latitude areas (Huang et al., 2012, 2015). The regional environment change has a close relationship with local population density and economic development level. Jiang and Hardee (2011) found that economic growth, technological changes, and population growth are the main elements of anthropogenic effects on emissions, which cannot be simulated easily by numerical models (Zhou et al., 2010). More recently, there have been some studies on understanding the implications of population growth, worker structure, and economic intensity for various scenarios of environmental change. The anthropogenic heating resulting from energy consumption has a significant continental-scale warming effect in mid-latitudes to high latitudes in winter based on model simulations (Huang et al., 1998; Higuchi et al., 1999; Shabbar et al., 2001; Zhang et al., 2013). Rapid industrialisation, urbanisation, population growth, and other anthropogenic activities have occurred in east Asia since the late 1980s (Jiang et al., 1998; Dong et al., 2007; Ge, 2009; Maya and David, 2010).

In previous studies, dynamic effects induced by internal variability have been proposed to interpret the rapid warming over continents and non-uniformity of local warming distribution (Wallace et al., 2012). The dynamic factors ex- 
hibit their influences on surface temperature changes in terms of circulation changes, such as the North Atlantic Oscillation (NAO), Pacific Decadal Oscillation (PDO), and Atlantic Multi-decadal Oscillation (AMO). Guan et al. (2015) found that the dynamically induced temperature and radiatively forced temperature had opposite contributions to the surface air temperature (SAT) during the warming "hiatus" over the Northern Hemisphere. Most of the obvious patterns occurred over mid-latitudes to high-latitudes where places are known to have been having noticeable zonally averaged warming since 1900 (Ji et al., 2014) and a phenomenon of enhanced warming over the semi-arid region (enhanced semiarid warming, ESAW) (Huang et al., 2012). The ESAW has been proposed to be caused by various factors, including changes in atmospheric circulations, sea surface temperature, interaction between land and atmosphere, and feedback from snow (Hu and Gao, 1994; Zhang et al., 2001; Huang et al., 2008; Guan et al., 2009; He et al., 2014); but the roles of different factors in the process of ESAW have not been confirmed.

In this study, the roles of different factors in the process of ESAW will be investigated using a recently developed methodology that can successfully identify and separate the dynamically induced temperature (DIT) and radiatively forced temperature (RFT) changes in the raw temperature data. Section 2 introduces the data sets used in this study. Section 3 provides a detailed description of the dynamical adjustment method. Section 4 shows enhanced warming in semi-arid regions and the behaviours of DIT and RFT over different regions of east Asia. It analyses the variability of DIT and the effects of major natural factors that dominate the dynamic temperature change, and shows the change of RFT. Section 5 lists all the main findings, followed by some discussion.

\section{Data sets and study area}

This study uses monthly precipitation, monthly mean temperature, and monthly daily maximum and minimum temperature from the land-only TS3.21 data set obtained from the Climate Research Unit at the University of East Anglia (Mitchell and Jones, 2005). The data cover the period of 1901-2012 with a high spatial resolution of $0.5^{\circ} \times 0.5^{\circ}$. The regionally average cold season mean-temperature trend of region $k$ is calculated using

$\bar{T}_{k}=\frac{\sum_{i=1}^{N_{k}} W_{k i} \times T_{k i}}{\sum_{i=1}^{N_{k}} W_{k i}}$,

where $N_{k}$ is the number of grids in region $k, T_{k i}$ is the cold season mean-temperature of grid $i$ in region $k$, and $W_{k i}=$ $\cos \left(\theta_{i} \times \pi / 180\right)$, with $\theta_{i}$ is the latitude of the grid $i$. The cold

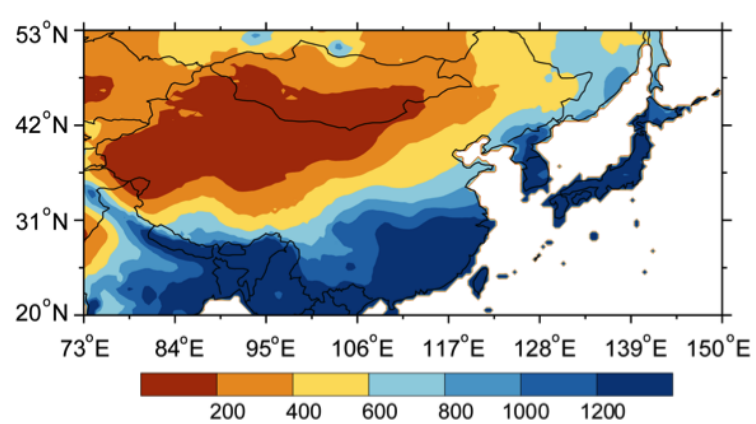

Figure 1. Spatial distribution of annual mean precipitation from 1961 to $1990\left(\mathrm{~mm}\right.$ year $\left.^{-1}\right)$.

season mean-temperature trend of region $k$ is calculated by a least squares method based on the time series of $\bar{T}_{k}$.

The contribution of cold season mean RFT (DIT) to raw cold season mean temperature is calculated as formula (2):

$\mathrm{CR}=\frac{1}{n} \sum_{i=1}^{n}\left(\widetilde{T}_{i}^{2} / T_{i}^{2}\right) \times 100 \%$

where $n$ is the number of years of temperature data set, $\widetilde{T}_{i}$ is the cold season mean radiatively forced temperature or dynamically induced temperature of year $i ; T_{i}$ is the raw cold season mean temperature of year $i$.

The study area is between 20 and $53^{\circ} \mathrm{N}$, and between 73 and $150^{\circ} \mathrm{E}$, which comprises much of east Asia. The distribution of 30-year averaged annual precipitation from 1961 to 1990 (Fig. 1) illustrates most of the semi-arid region (annual precipitation between 200 and $600 \mathrm{~mm}_{\text {year }}{ }^{-1}$ ) located in the northeast; and most of the arid region is in the northwest. It exhibits a generally increased pattern of annual precipitation from northwest to southeast. Although precipitation is related to surface temperature, the long-term mean precipitation is the simplest index for classifying climate regions (Huang et al., 2012).

\section{Dynamical adjustment methodology}

The dynamical adjustment method was first proposed by Wallace et al. (2012) and used to analyse the non-uniformity of the spatial warming over the Northern Hemisphere. The SAT, or the raw temperature data, are divided into two parts by the dynamical adjustment method: DIT and RFT. Wallace et al. (2012) claimed the dynamical adjustment method can remove the dynamic component of the SAT induced by the atmospheric circulation pattern from the raw SAT in the cold season (November-April) over land areas poleward of $20^{\circ} \mathrm{N}$.

The dynamical adjustment methodology used in this study has been improved by Smoliak et al. (2015). The exact process of partial least squares (PLS) is to derive monthly dynamical adjustment of the Northern Hemisphere land surface 


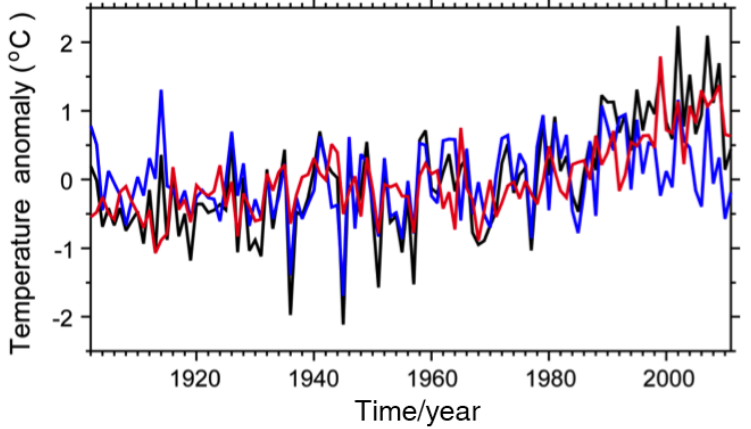

Figure 2. Time series of regionally averaged temperature anomalies of raw (black), dynamically induced (blue), and radiatively forced (red) temperatures in the cold season (November to March) from 1902 to 2011 over east Asia.

temperature field in a point-wise manner, namely, the temperature time series of each grid point is a predictand. The sea level pressure (SLP) data are standardised and the temperature time series are high-pass filtered by removing the cold season mean from the mean for each month within a given cold season and then are standardised prior to carrying out the following dynamical adjustment steps. (1) Correlate the grid-point temperature time series with the SLP field to generate a one-point cross-correlation map. (2) Project the monthly SLP field onto the correlation pattern, weight each grid point by the cosine of its latitude to obtain the first PLS predictor time series Z1. (3) Regress this PLS predictor Z1 out of both the each grid-point temperature time series and its SLP predictor field, using conventional least squares fitting procedures, which can obtain a residual temperature time series and residual SLP field. Repeat these steps on the residual temperature time series and residual SLP field to obtain the respective PLS predictor Z2 and Z3, .., Zn, which are mutually orthogonal, taking care to high-pass filter each successive residual temperature time series prior to calculating correction patterns (step 1). In our study, the improved dynamical adjustment methodology (Smoliak et al., 2015) has been applied to the temperature data set and three predictors are retained, which are determined by cross-validation.

Following the process stated above, the components associated with changes of atmospheric circulation patterns that are expressed in terms of SLP are partitioned, and referred to as DIT variability. The residual part is associated with radiatively forced factors, called the RFT. The RFT is considered as a result of build-up of greenhouse gases (GHGs), stratospheric ozone depletion, volcanic eruption, aerosol emission, and local anthropogenic forcing. In the semi-arid region of east Asia that we are interested in, non-radiative factors resulting from thermodynamic processes are also a part of RFT. As their proportion is small over the semi-arid regions, their effects in RFT are ignored in this study. Therefore, we can use the dynamical adjustment method to identify the roles of DIT and RFT in the process of enhanced warming.

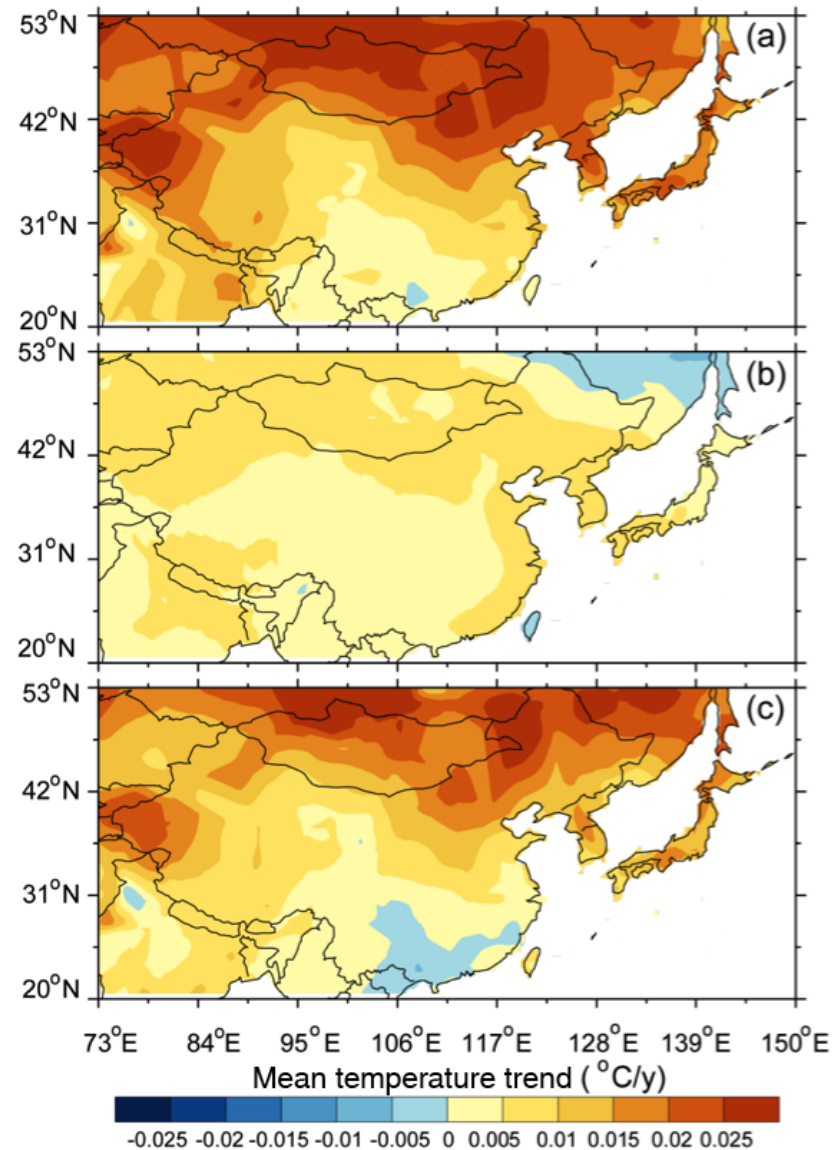

Figure 3. Spatial distribution of cold season trend of raw (a), dynamically induced (b), and radiatively forced (c) temperatures from 1902 to 2011 over east Asia.

\section{Results analysis}

Figure 2 compares the variation of cold season mean SAT of raw, dynamically and radiatively forced temperatures over east Asia in the period of 1902-2011. The curves exhibit a warming trend in the past century as a whole and an obvious warming from the 1970s to the 1990s. Then, there appears to have been a stop in the raw temperature change (black line) from about 2000 until now. The DIT (blue line) exhibits obvious decadal variability, with a relatively warming period from the 1970s to the 1990s and an obvious cooling period from 2000 to 2011 in the cold season. The RFT (red line) shows a rapid increasing rate since the late 1970s, which is consistent with the raw temperature data. The different evolutions of DIT and RFT indicate that the DIT and RFT played different roles in determining the raw temperature variability.

Figure 3 shows the spatial distribution of raw, DIT, and RFT trends over east Asia in the period of 1902-2011. Figure 3a exhibits a gradually increasing warming pattern from south to north and a strong warming trend located over northern east Asia, especially in Mongolia and northeast China. 


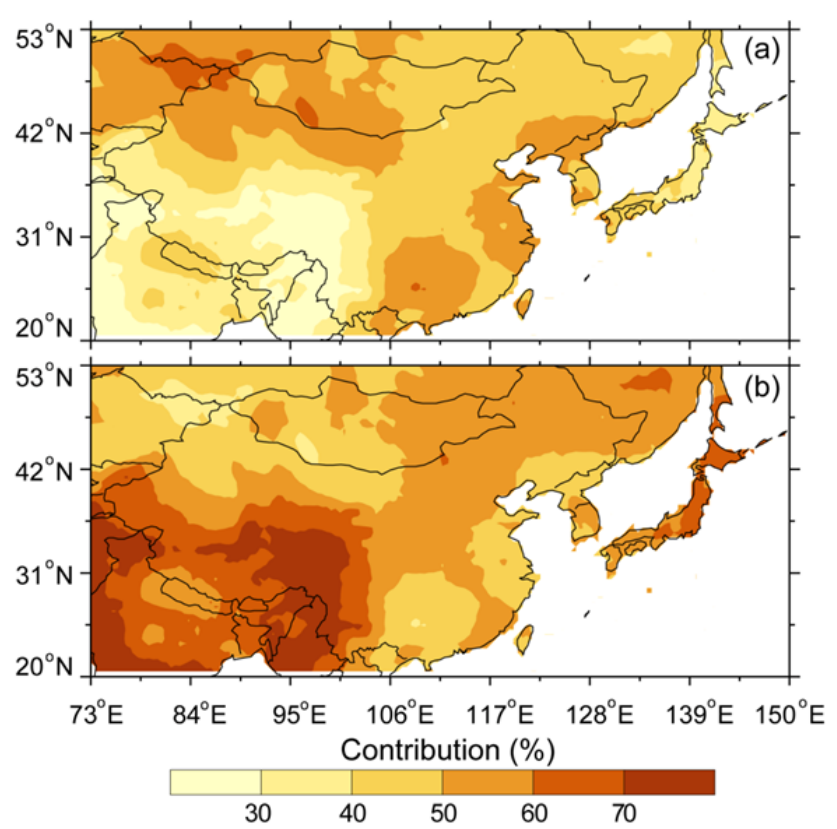

Figure 4. Spatial distribution of contribution of dynamically induced (a) and radiatively forced (b) temperatures to raw cold-season temperature from 1902 to 2011 over east Asia.

The rate of warming was less than $0.005^{\circ} \mathrm{C}_{\text {year }}{ }^{-1}$ in the south of $40^{\circ} \mathrm{N}$, with a small scale of cooling region over the southwest. The distribution of DIT trend (Fig. 3b) shows a basic warming background of east Asia. The warming rate over most areas was less than $0.01{ }^{\circ} \mathrm{C}_{\text {year }}{ }^{-1}$, with a higher value in the northern part than in the southern part of east Asia as a whole, and a cooling scale was located in the northeast of east Asia. The distribution of the RFT trend (Fig. 3c) exhibits a similar distribution to that of the raw temperature. It shows an obvious warming over the northern area of east Asia, which reached $0.025^{\circ} \mathrm{C}_{\text {year }}{ }^{-1}$ in some regions. A larger scale of cooling located in the southern region demonstrates that the cooling in the raw temperature was due to the radiative factors. The difference of DIT trend distribution from RFT indicates that the influence of radiative forcing on regional temperature changes was quite different to the influence of dynamic factors during the period of 1902-2011.

Figure 4 gives the distributions of contributions of DIT and RFT to the raw temperature in the cold season over east Asia in the period of 1902-2011. The dynamic contribution to the raw temperature (Fig. 4a) has high values over the northwest and along the coastal area of southeast China, but the peak value is much less than its radiative value. In the spatial distribution of RFT contribution (Fig. 4b), the positive centres were located over the northeast and southwest areas, and the values were much higher than those in Fig. 4a. Figure 4 illustrates that regional temperature is mostly determined by RFT. This regional discrepancy is confirmed by the contributions of DIT (blue line) and RFT (red line) to the cold

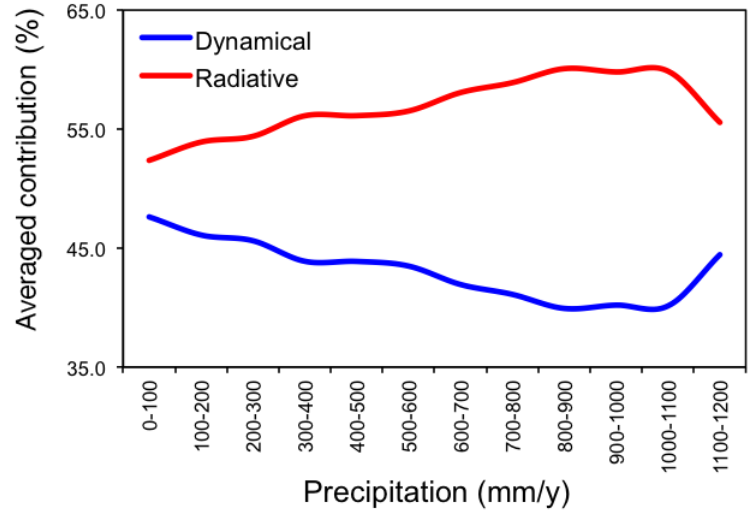

Figure 5. Contributions of dynamically induced (blue) and radiatively forced (red) temperatures to the raw temperature as a function of annual precipitation in the cold season from 1902 to 2011 over east Asia.

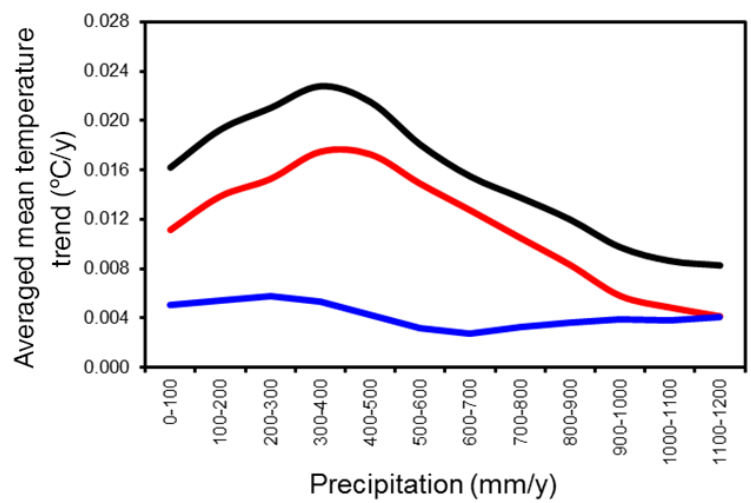

Figure 6. Regionally averaged cold season mean-temperature trend as a function of annual precipitation for raw (black), dynamically induced (blue), and radiatively forced (red) temperatures in the cold season from 1902 to 2011 over east Asia.

season raw temperature as a function of annual precipitation over east Asia (Fig. 5). Figure 5 shows that the RFT made a greater contribution than the DIT over the whole region. The contribution of RFT increased as the annual precipitation increased. Opposite to the radiative contribution, the dynamical contribution decreased with the increase of annual precipitation.

According to Huang et al. (2012), the enhanced warming occurred over the semi-arid regions. Figure 6 shows the longterm trends of DIT and RFT as a function of annual-mean precipitation. It illustrates that the RFT made a major contribution to the regional variation and showed a similar curve as the raw temperature over different regions. Both the raw data and RFT reached the peak in the area of 300-400 $\mathrm{mm}_{\text {year }}{ }^{-1}$. The fact that the peaks of cold season mean-temperature trend of both raw data and RFT occurred over semi-arid regions indicates that the radiative factors had dominant roles in the process of enhanced warming over the semi-arid re- 

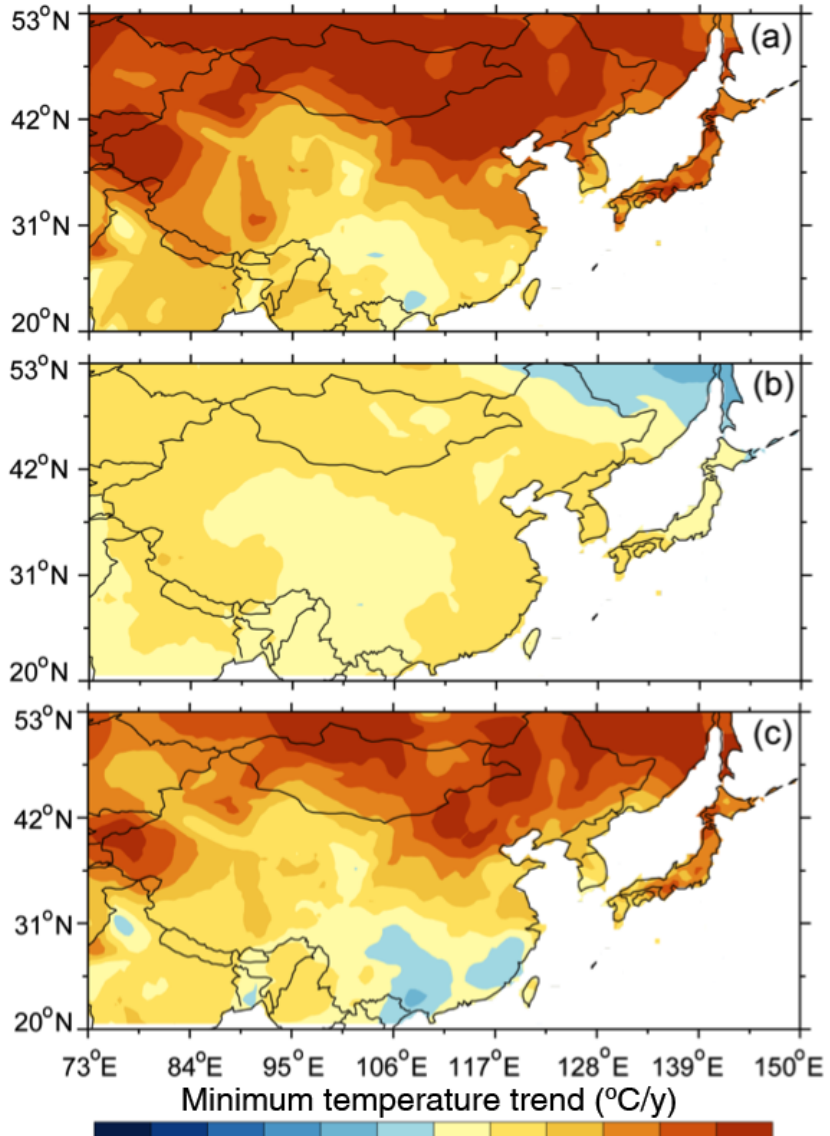

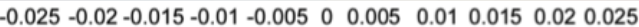

Figure 7. Same as Fig. 3, except for daily minimum temperatures.

gions. Conversely, the DIT trend did not show an obvious difference as a function of annual mean precipitation. It kept a mean rate of $0.005^{\circ} \mathrm{C}_{\text {year }}{ }^{-1}$, which is far lower than the $0.017^{\circ} \mathrm{C}$ year $^{-1}$ of the highest value in the drylands of the RFT trend. The greater warming rate in the semi-arid region that appeared in both raw temperature and RFT indicated that enhanced warming occurring in drylands is mainly associated with RFT. This extends understanding of the ESAW (Huang et al., 2012), and suggests that the role of radiative forcing was critical in the process of warming over east Asia. These results are not limited to the monthly-mean temperatures. Figure 7 shows the distributions of raw, dynamically induced, and radiatively forced daily minimum cold season mean-temperature trends over east Asia in the period of 1902-2011. The raw daily minimum temperature illustrates a similar distribution to the raw monthly-mean temperature, with a stronger warming trend over northern east Asia, especially over Mongolia and northeast China. The dynamically induced daily minimum temperature (Fig. 7b) shows a warming pattern over most areas, with a small cooling in the area along the northeast China. The RFT trend (Fig. 7c) had an
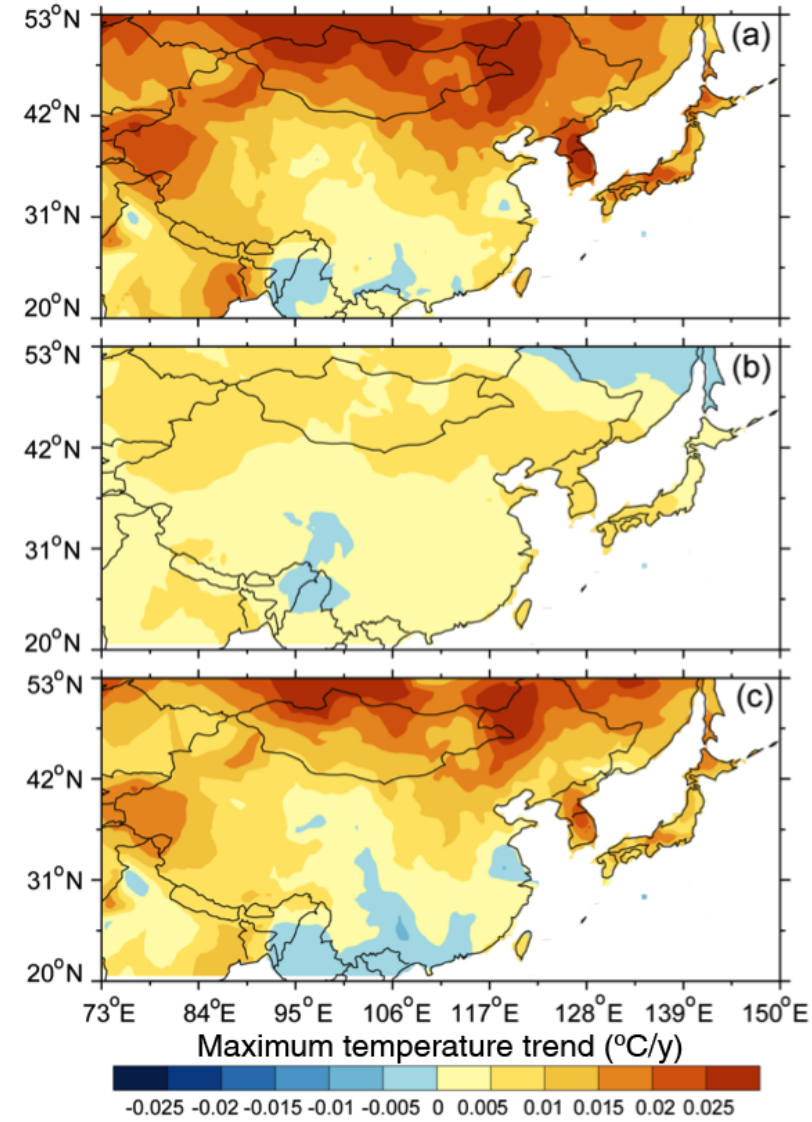

Figure 8. Same as Fig. 3, except for daily maximum temperatures.

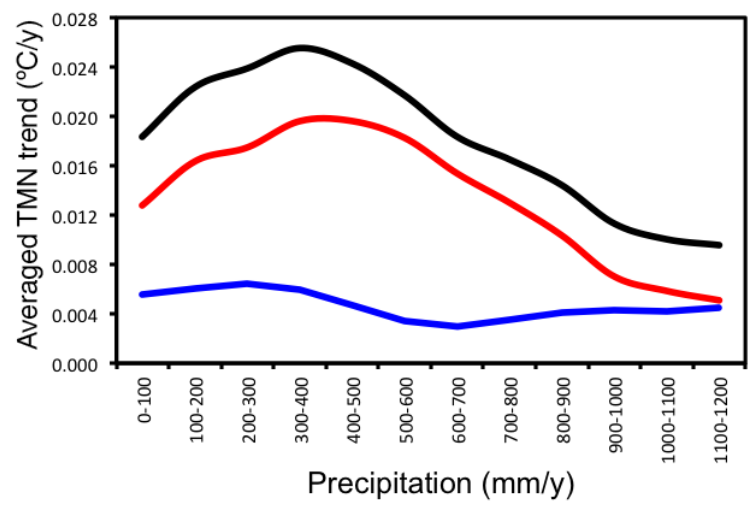

Figure 9. Same as Fig. 6, except for daily minimum temperature (TMN).

obvious warming over the northern area, with a smaller cooling over south China than in the monthly-mean temperature.

Figure 8 shows the distributions of raw, dynamically induced, and radiatively forced daily maximum cold season mean-temperature trends over east Asia in the period of 1902-2011. The raw daily maximum cold season meantemperature trend (Fig. 8a) was positive over northern east 


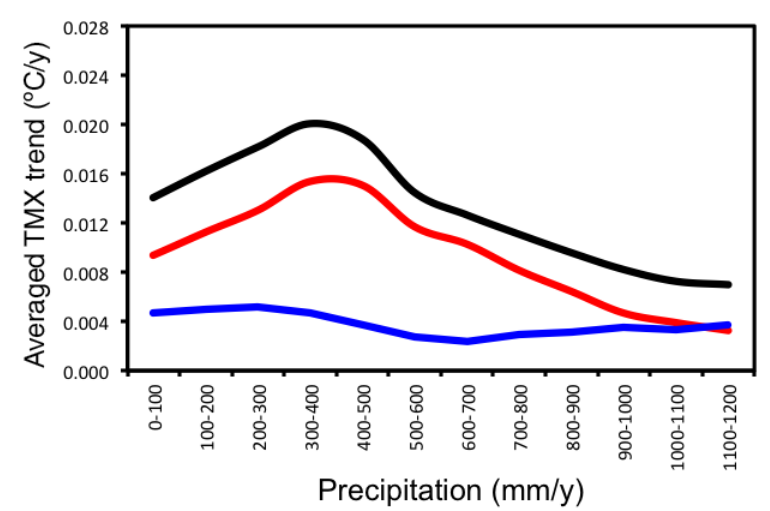

Figure 10. Same as Fig. 6, except for daily maximum temperature (TMX).
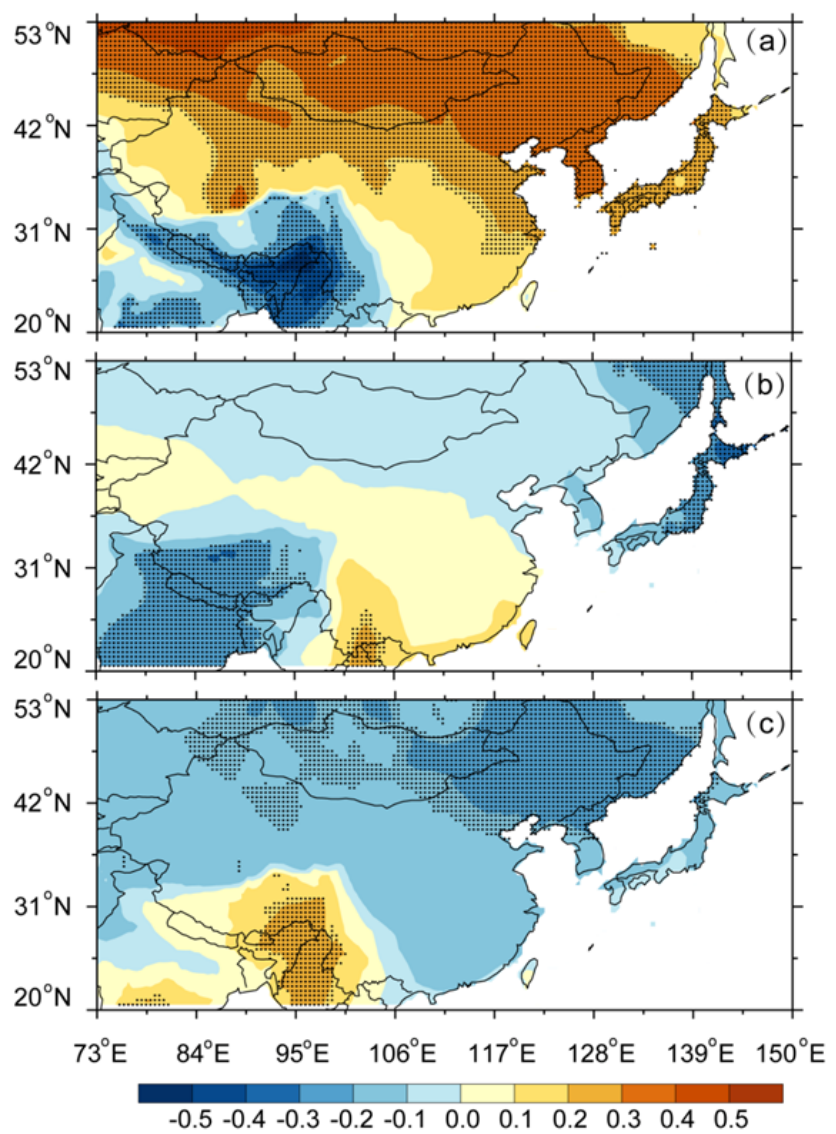

Figure 11. Spatial distribution of the correlation coefficient between detrended dynamically induced temperature and detrended NAO (a), PDO (b), and AMO (c) in the cold season from 1902 to 2011 over east Asia. The stippling indicates the $95 \%$ confidence level according to a two-tailed Student's $t$ test.

Asia, especially over Mongolia; but the warming extent was apparently less than that in the daily minimum temperature. The cooling in the southern part was larger than that in the daily minimum temperature. The dynamically induced daily

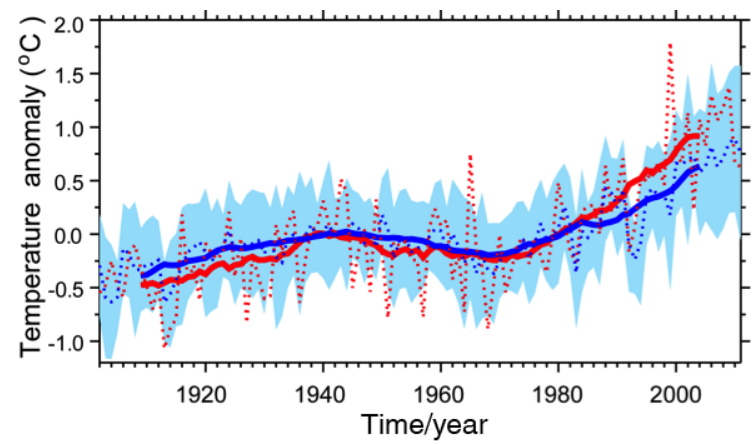

Figure 12. Time series of radiatively forced temperature (red) and ensemble-mean CMIP5 simulations (blue) based on a 15-year running mean in the cold season from 1902 to 2011 over east Asia. The blue shading indicates the standard deviation of the CMIP5simulated field.

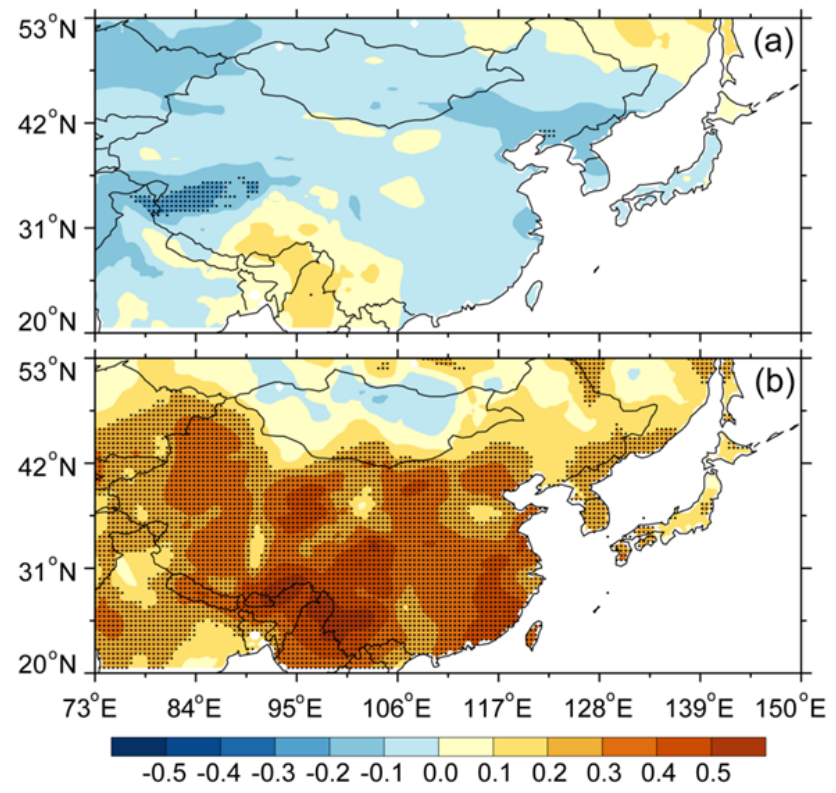

Figure 13. Spatial distribution of correlation coefficient between ensemble-mean CMIP5 simulations and dynamically induced temperature (a), and between ensemble-mean CMIP5 simulations and radiatively forced temperature (b) in the cold season from 1902 to 2011 over east Asia.

maximum temperature (Fig. 8b) shows a slight warming over most areas, with a cooling located in northeast China. The RFT trend (Fig. 8c) exhibits an obvious warming over the northern area, with a larger cooling scale over south China than daily minimum temperature, shown in Fig. 7c.

In order to distinguish the contributions to regionally averaged cold season mean-temperature trends, raw, DIT, and RFT minimum and maximum trends are shown as a function of annual-mean precipitation in Figs. 9 and 10, respectively. The daily minimum (Fig. 9) had a higher warming rate than the daily maximum (Fig. 10) over all regions, espe- 


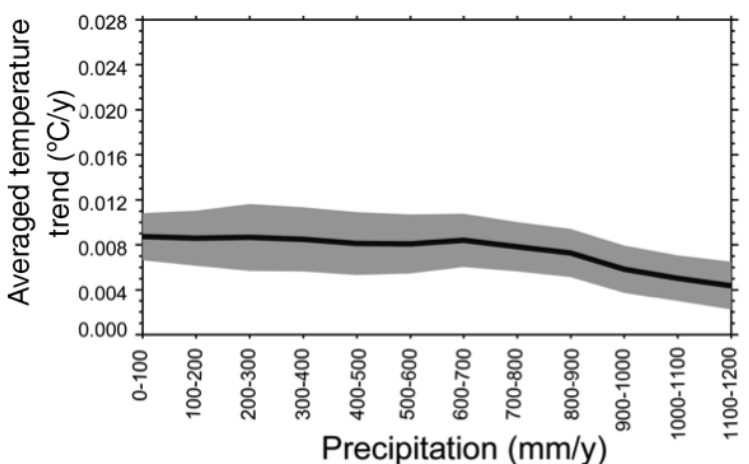

Figure 14. Regional averaged cold season mean-temperature trend as a function of climatological annual mean precipitation over east Asia for ensemble-mean CMIP5 simulations in cold season from 1902 to 2011, shading denotes $95 \%$ confidence intervals.

cially in the drylands. The peaks of RFT over the drylands in both daily minimum and maximum temperatures indicate the dominating role of radiative effects in the regional warming. Similar to monthly-mean temperature, the DIT trend did not show much variation with increasing annual-mean precipitation in both daily minimum and maximum temperatures. The higher values of RFT of both daily minimum and maximum temperatures in the drylands emphasise the major role of RFT in the local enhanced warming process.

The DIT was mainly dominated by major dynamic factors, such as the NAO (Li et al., 2013), PDO (Trenberth and Hurrell, 1994; Kosaka and Xie, 2013), and AMO (Wyatt et al., 2012; Wyatt and Curry, 2014). The correlation coefficients between DIT and NAO/PDO/AMO (Fig. 11) illustrate the influences of these dynamic factors. Figure 11a shows the distribution of the correlation coefficient between the NAO and the DIT. It exhibits positive correlations over most of the east Asia region, significant at the $95 \%$ confidence level over Mongolia, Inner Mongolia, and northeast China; and it exhibits negative correlations over India and southwest China, also significant at the $95 \%$ confidence level. This indicates a strong positive influence of the NAO on the DIT over the northern area and the negative effect over the southwest of east Asia. Figure 11b is the correlation coefficient between PDO and DIT. Only the negative correlation coefficients over the boundary of China and India pass the confidence level of $95 \%$. In south China and north China, there were positive and negative patterns, respectively. Meanwhile, the negative correlative coefficients between the AMO index and DIT (Fig. 11c) covered most of the region of east Asia, except for a small positive region in the southwest of east Asia. The general spatial distribution is opposite to the distribution of the NAO.

The RFT variability is always considered as a result of GHGs, land cover change, human activities, clouds (Huang et al., 2005, 2006), and aerosols (Huang et al., 2011; Li et al., 2011). The fast industrialisation process over east Asia

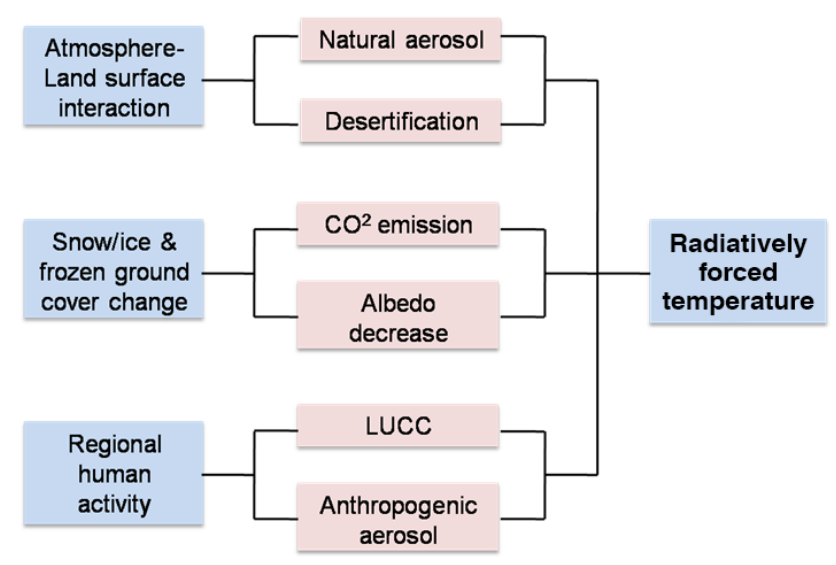

Figure 15. Schematic diagram of radiatively forced temperature. LUCC represents land use and land cover change.

produced more anthropogenic GHGs and aerosols, and impacted the local climate change (Qian et al., 2009, 2011). In order to manifest the effects of radiative in RFT, a comparison between RFT and a 20-model ensemble mean of CMIP5 simulations (Table 1) (Taylor et al., 2012) over the east Asia is plotted (Fig. 12), which shows a notable consistent warming trend between RFT and simulated SAT from the 1970s to the late 1990. The distributions of correlation coefficients of DIT and RFT with simulated temperature of CMIP5 in the period of 1902-2011 are expressed in Fig. 13a and b. Figure 13a exhibits a negative pattern over most of the area except for the boundary between northwest China and Russia and southwest east Asia; but in Fig. 13b, the correlation coefficient of RFT with CMIP5 ensemble mean temperature has a positive pattern over most of China, which passes the $95 \%$ confidence level, excluding the northeast of China and Mongolia. It indicates that the forced temperature changes in CMIP5 have a closer relationship with RFT and DIT. The high positive correlation coefficient between RFT and the multi-model ensemble mean of CMIP5 indicates that the radiatively forced influence takes a major proportion in simulated temperature change. Multi-model ensemble mean cold season mean-temperature trends shown as a function of annual precipitation in Fig. 14 contrast the regional RFT trends over the drylands shown in Fig. 6. It illustrates that the enhanced warming over the semi-arid regions led by the RFT does not appear in the multi-model ensemble mean temperature. In contrast to observations, the CMIP5 simulations exhibit a uniform temperature change over east Asia. The significant difference between RFT and simulated temperatures over the drylands indicates that the enhanced warming over semi-arid region was not mainly related to radiative forcing produced in models, such as GHGs, land cover change, and aerosol. It is more likely related to regional factors not well represented in the models. 
Table 1. CMIP5 models examined in this study.

\begin{tabular}{ll}
\hline Model name & Modelling centre \\
\hline BCC-CSM1.1 & Beijing Climate Center, China \\
CanESM2 & Canadian Centre for Climate, Canada \\
CanESM2 & Canadian Centre for Climate, Canada \\
CCSM4 & National Center for Atmospheric Research, USA \\
CNRM-CM5 & Centre National de Recherches Météorologiques, France \\
CSIRO-Mk3.6.0 & Commonwealth Scientific and Industrial Research, Australia \\
GFDL-CM3 & Geophysical Fluid Dynamics Laboratory, USA \\
GFDL-ESM2G & Geophysical Fluid Dynamics Laboratory, USA \\
GFDL-ESM2M & Geophysical Fluid Dynamics Laboratory, USA \\
GISS-E2-R & NASA Goddard Institute for Space Studies, USA \\
HadGEM2-CC & Met Office Hadley Centre, UK \\
HadGEM2-ES & Met Office Hadley Centre, UK \\
INM-CM4 & Institute for Numerical Mathematics, Russia \\
IPSL-CM5A-LR & Institute Pierre Simon Laplace, France \\
IPSL-CM5A-MR & Institute Pierre Simon Laplace, France \\
MIROC-ESM & Japan Agency for Marine-Earth Science and Technology, Japan \\
MIROC-ESM-CHEM & Japan Agency for Marine-Earth Science and Technology, Japan \\
MIROC5 & Atmosphere and Ocean Research Institute, Japan \\
MPI-ESM-LR & Max Planck Institute for Meteorology, Germany \\
MRI-CGCM3 & Meteorological Research Institute, Japan \\
NorESM1-M & Norwegian Climate Centre, Norway \\
\hline
\end{tabular}

\section{Summary and discussion}

Our results provide evidence that the enhanced warming in the drylands was induced by the RFT. The DIT and RFT extracted from the raw temperature had different contributions in the process of temperature change. For the regionally averaged values, the DIT and RFT contributed 44 and $56 \%$ to the SAT over east Asia, respectively. The DIT that was dominated by the NAO, PDO, and AMO varied on decadal timescales. The RFT changes were the major contributions to the global-scale warming trend and the regional-scale enhanced warming in the semi-arid regions. Guan et al. (2015) found that the radiatively forced temperature has shown a warming trend in the past decades. The local processes dominated the enhanced warming in the semi-arid regions. These possible local processes have been listed in Fig. 15.

The regional RFT was mainly induced by the interaction among atmosphere, land surface, snow/ice and frozen ground cover change, and regional human activities. For example, the drying of sandy or rocky soil by higher temperatures would increase surface albedo, reflecting more solar radiation back to the space. And the substantial decline of snow/ice and frozen ground change in the past 30 years, particularly from early spring through summer (Zhai and Zhou, 1997), may cause the surface temperature to increase in the cold season via the influence on albedo. The thickness of seasonally frozen ground has decreased in response to winter warming (Lemke et al., 2007), which will emit more $\mathrm{CO}_{2}$ into the atmosphere. The net radiation in the semi-arid regions will become a radiation sink of heat relative to the surrounding regions. Mulitza et al. (2010) found that local anthropogenic dust aerosols associated with human activities (Chen et al., 2010) such as agriculture and industrial activity accounted for $43 \%$ of the total dust burden in the atmosphere. The radiatively forced effect of aerosol may be another key process in the enhanced warming of the semi-arid region. More investigations are needed to quantify the contribution of different local processes.

Our results also explained the co-existence of regional warming and the warming hiatus across the entire Northern Hemisphere. The major interpretation of the warming trend slowdown (WTS) claimed that natural variability played an important role in global temperature variability (Easterling and Wehner, 2009; Wyatt et al., 2012, Wyatt and Curry, 2014; Kosaka and Xie, 2013). The RFT had a warming contribution which offset the cooling effect of DIT, and resulted in a hiatus over the Northern Hemisphere (Guan et al., 2015). According to the results of our study, the RFT had made a major contribution to global warming, where the most obvious warming appeared in the drylands. And we conclude that the long-term global-mean SAT warming trend was mainly related to the radiative forcing produced by the global, wellmixed GHGs. However, the regional anthropogenic radiative forcing caused the enhanced warming in the semi-arid regions. Therefore, the hiatus as a phenomenon of global scale was not in conflict with the regionally enhanced warming in the semi-arid regions. 
Acknowledgements. The authors thank two anonymous reviewers for their constructive comments. This work was supported by the National Basic Research Program of China (2012CB955301), the National Science Foundation of China (41305009, 41575006, and 41521004), the China 111 project (No. B 13045), and Fundamental Research Funds for the Central Universities (lzujbky-2015-2, lzujbky-2015-ct03). The authors acknowledge the World Climate Research Programme's (WCRP) Working Group on Coupled Modelling (WGCM), the Global Organization for Earth System Science Portals (GO-ESSP) for producing the CMIP5 model simulations and making them available for analysis, and the Climate Explorer for making the NAO, PDO, and AMO indices available for download (http://climexp.knmi.nl/).

Edited by: H. Wang

\section{References}

Chen, B., Huang, J., Minnis, P., Hu, Y., Yi, Y., Liu, Z., Zhang, D., and Wang, X.: Detection of dust aerosol by combining CALIPSO active lidar and passive IIR measurements, Atmos. Chem. Phys., 10, 4241-4251, doi:10.5194/acp-10-4241-2010, 2010.

Dong, W., Chou, J., and Feng, G.: A New Economic Assessment Index for the Impact of Climate Change on Grain Yield, Adv. Atmos. Sci., 24, 336-342, doi:10.1007/s00376-007-0336-y, 2007.

Easterling, D. R. and Wehner, M. F.: Is the climate warming or cooling?, Geophys. Res. Lett., 36, L08706, doi:10.1029/2009GL037810, 2009.

Ge, Y.: Globalization and Industry Agglomeration in China, World Development, 37, 550-559, doi:10.1016/j.worlddev.2008.07.005, 2009.

Guan, X., Huang, J., Guo, N., Bi, J., and Wang, G.: Variability of soil moisture and its relationship with surface albedo and soil thermal parameters over the Loess Plateau, Adv. Atmos. Sci., 26, 692-700, 2009.

Guan, X., Huang, J., Guo, R., and Lin, P.: The role of dynamically induced variability in the recent warming trend slowdown over the Northern Hemisphere, Sci. Rep., 5, 12669, doi:10.1038/srep12669, 2015.

He, Y., Huang, J., and Ji, M.: Impact of land-sea thermal contrast on interdecadal variation in circulation and blocking, Clim. Dynam., 43, 3267-3279, 2014.

Higuchi, K., Huang, J., and Shabbar, A.: A wavelet characterization of the North Atlantic Oscillation variation and its relationship to the North Atlantic sea surface temperature, Int. J. Climatol., 19, 1119-1129, doi:10.1002/(SICI)10970088(199908)19:10<1119::AID-JOC414>3.0.CO;2-7, 1999.

$\mathrm{Hu}, \mathrm{Y}$. and Gao, Y.: Some new understandings of processes at the land surface in arid area from the HEIFE, Acta. Meteorol. Sin., 52, 285-296, 1994.

Huang, J., Higuchi, K., and Shabbar, A.: The relationship between the North Atlantic Oscillation and El Niño-Southern Oscillation, Geophys. Res. Lett., 25, 2707-2710, 1998.

Huang, J., Minnis, P., Lin, B. , Yi, Y., Khaiyer, M., Arduini, R., Fan, A., and Mace, G.: Advanced retrievals of multilayered cloud properties using multispectral measurements, J. Geophys. Res., 110, D15S18, doi:10.1029/2004JD005101, 2005.
Huang, J., Minnis, P., Lin, B., Yi, Y., Sun-Mack, S., Fan, T., and Ayers, J.: Determination of ice water path in ice-over-water cloud systems using combined MODIS and AMSR-E measurements, Geophys. Res. Lett., 33, L21801, doi:10.1029/2006GL027038, 2006.

Huang, J., Zhang, W., Zuo, J., Bi, J., Shi, J., Wang, X., Chang, Z., Huang, Z., Yang, S., and Zhang, B.: An overview of the semi-arid climate and environment research observatory over the Loess Plateau, Adv. Atmos. Sci., 25, 906-921, 2008.

Huang, J., Fu, Q., Zhang, W., Wang, X., Zhang, R., Ye, H., and Warren, S.: Dust and black carbon in seasonal snow across northern China, B. Am. Meteorol. Soc., 92, 175-181, doi:10.1175/2010BAMS3064.1, 2011.

Huang, J., Guan, X., and Ji, F.: Enhanced cold-season warming in semi-arid regions, Atmos. Chem. Phys., 12, 5391-5398, doi:10.5194/acp-12-5391-2012, 2012.

Huang, J., Ji, M., Liu, Y., Zhang, L., and Gong, D.: Review of climate change research in arid and semi-arid regions, Advances in Climate Change Research, 9, 9-14, 2013 (in Chinese).

Huang, J., Yu, H., Guan, X., Wang, G., and Guo, R.: Accelerated dryland expansion under climate change, Nature Climate Change, doi:10.1038/nclimate2837, 2015.

Ji, F., Wu, Z., Huang, J., and Chassignet, E. P.: Evolution of land surface air temperature trend, Nature Climate Change, 4, 462466, 2014.

Jiang, K., Hu, X., Matsuoka, Y., and Morita, T.: Energy Technology Changes and $\mathrm{CO}_{2}$ Emission Scenarios in China, Environment Economics and Policy Studies 1, 141-160, doi:10.1007/BF03353898, 1998.

Jiang, L. and Hardee, K.: How do recent population trends matter to climate change?, Popul. Res. Policy Rev., 30, 287-312, 2011.

Kosaka, Y. and Xie, S. P.: Recent global-warming hiatus tied to equatorial Pacific surface cooling, Nature, 501, 403-407, 2013.

Lemke, P., Ren, J., Alley, R. B., Allison, I., Carrasco, J., Flato, G., Fujii, Y., Kaser, G., Mote, P., Thomas, R. H., and Zhang, T.: Observations: changes in snow, ice and frozen ground, in: Climate change: the physical science basis. Contribution of Working Group I to the fourth assessment report of the Intergovernmental Panel on Climate Change, edited by: Solomon, S., Qin, D., Manning, M., Chen, Z., Marquis, M., Averyt, K. B., Tignor, M., and Miller, H. L., Cambridge University Press, Cambridge, United Kingdom and New York, NY, USA, 372-374, 2007.

Li, J. P., Sun, C., and Jin, F. F.: NAO implicated as a predictor of Northern Hemisphere mean temperature multidecadal variability, Geophys. Res. Lett., 40, 5497-5502, 2013.

Li, Z., Niu, F., Fan, J., Liu, Y., Rosenfeld, D., and Ding, Y.: Long-term impacts of aerosols on the vertical development of clouds and precipitation, Nat. Geosci., 4, 888-894, doi:10.1038/NGEO1313, 2011.

Maya, F. and David, I. L.: Industrialization, pollution, and infant mortality, Environment and Development Economics, 15, 557584, doi:10.1017/S1355770X10000185, 2010.

Mitchell, T. D. and Jones, P. D.: An improved method of constructing a database of monthly climate observations and associated high-resolution grids, Int. J. Climatol., 25, 693-712, 2005.

Mulitza, S., Heslop, D., Pittauerova, D., Fischer, H. W., Meyer, I., Stuut, J. B., Zabel, M., Mollenhauer, G., Collins, J. A., and Kuhnert, H.: Increase in African dust flux at the onset of commercial agriculture in the Sahel region, Nature, 466, 226-228, 2010. 
Qian, Y., Gustafson Jr., W. I., Leung, L. R., and Ghan, S. J.: Effects of soot-induced snow albedo change on snowpack and hydrological cycle in western United States based on Weather Research and Forecasting chemistry and regional climate simulations, J. Geophys. Res., 114, D03108, doi:10.1029/2008JD011039, 2009.

Qian, Y., Flanner, M. G., Leung, L. R., and Wang, W.: Sensitivity studies on the impacts of Tibetan Plateau snowpack pollution on the Asian hydrological cycle and monsoon climate, Atmos. Chem. Phys., 11, 1929-1948, doi:10.5194/acp-11-19292011, 2011.

Shabbar, A., Huang, J., and Higuchi, K.: The relationship between the wintertime North Atlantic Oscillation and blocking episodes in the North Atlantic, Int. J. Climatol., 21, 355-369, doi:10.1002/joc.612, 2001.

Smoliak, B. V., Wallace, J. M., Lin, P., and Fu, Q.: Dynamical adjustment of the Northern Hemisphere surface air temperature field: methodology and application to observations, J. Climate, 28, 1613-1629, 2015.

Taylor, K. E., Stouffer, R. J., and Meehl, G. A.: An overview of CMIP5 and the experiment design, B. Am. Meteorol. Soc., 4, 485-498, 2012.

Trenberth, K. E. and Hurrell, J. W.: Decadal atmosphere-ocean variations in the Pacific, Clim. Dynam., 9, 303-319, 1994.

Wallace, J. M., Fu, Q., Smoliak, B. V., Lin, P., and Johanson, C. M.: Simulated versus observed patterns of warming over the extratropical Northern Hemisphere continents during the cold season, P. Natl. Acad. Sci., 109, 14337-14342, 2012.
White, R. P. and Nackoney, J.: Drylands, people, and ecosystem goods and services: a web-based geospatial analysis (PDF version), World Resources Institute, available at: http://s1. downloadmienphi.net/file/downloadfile6/151/1384326.pdf (last access: 30 January 2012), 2003.

Wyatt, M. G. and Curry, J. A.: Role for Eurasian Arctic shelf sea ice in a secularly varying hemispheric climate signal during the 20th century, Clim. Dynam., 42, 2763-2782, 2014.

Wyatt, M. G., Kravtsov, S., and Tsonis, A. A.: Atlantic multidecadal Oscillation and Northern Hemisphere's climate variability, Clim. Dynam., 38, 929-949, 2012.

Zhai, P. and Zhou, Q.: The change of northern hemisphere snow cover and its impact on summer rainfalls in China, Q. J. Appl. Meteorol., 8, 231-235, 1997 (in Chinese).

Zhang, G., Cai, M., and Hu, A.: Energy consumption and the unexplained winter warming over northern Asia and North America, Nature Climate Change, 3, 466-470, 2013.

Zhang, Q., Wei, G., and Huang, R.: Observation and study of atmospheric drag coefficients in Dunhuang, Sci. China Ser. D, 31, 783-792, 2001 (in Chinese).

Zhou, L., Dickinson, R. E., Dai, A., and Dirmeyer, P.: Detection and attribution of anthropogenic forcing to diurnal temperature range changes from 1950 to 1999: comparing multi-model simulations with observations, Clim. Dynam., 35, 1289-1307, 2010. 